\title{
Villoo Morawala Patell
}

Whether she's wooing investors, building a patent portfolio, critiquing multinational pharmaceutical firms or tackling hereditary diseases in her native community, Avesthagen CEO Villoo Morawala Patell brings a unique mix of dynamism and intellectual verve to the table.

Seven months ago, global investors pumped $\$ 32$ million into Avesthagen, a multidisciplinary biotech firm in Bangalore, India. Participants included Limagrain, of Chappes, France, the world's fourth-largest seeds company, and food giant Danone, of Paris. In April, another $\$ 5$ million came from a US-based private equity firm advised by India's Jacob Ballas Capital, bringing total overseas investment to $>35 \%$.

"In India, venture capitalists rarely look at start-ups, especially in the life science sector," says Chandrasekhar Kundur, senior vice president of Venture Capital in Hyderabad, India.

Which suggests that Avesthagen is a different kind of start-up, and that 52-year-old Villoo Morawala Patell, the company's founder, managing director and vice chairperson, is a different kind of leader.

Although most Indian biotechs survive by doing reverse engineering or contract work, Patell set out to give Avesthagen a strong focus on innovative research and development $(\mathrm{R} \& \mathrm{D})$ in diverse areas, such as agbiotech, nutraceuticals, pharmaceuticals and diagnostics. Today, it already has 140 patents - either filed or in the pipeline-which represent the first Indian-generated intellectual property (IP) to challenge Monsanto's (St. Louis, MO) grip over agbiotech. Avesthagen is focused on "intensifying our intellectual property through product commercialization," says Patell. "We do not build things that already exist."

Her entrepreneurial path began at the International Crops Research Institute for Semi-Arid Tropics (ICRISAT) in Hyderabad in the 1980s. While she was working there, an opportunity arose for Patell to get a PhD in France. She was intrigued enough to take up the offer, taking her two children and husband with her. As she left, her mother told her, "Villoo, I do not know if you are doing the right thing; but whatever you do, make sure it takes you to the top."

Although Patell's PhD studies in plant molecular biology at Louis Pasteur University, in Strasbourg, ignited a desire to be creative, it was her nine months as a postdoc at the University of Ghent, in Ghent, Belgium, working with scientists "from every country," that really sparked her entrepreneurial spirit. When she returned to India, her mind was set. "I wanted to create a truly research-based company in India," she says.

That would take time. For the next four years, she did rice research as a Rockefeller grantee at the National Centre for Biological Sciences (NCBS) and as an emeritus professor at the University of Agricultural Sciences, both in Bangalore, India. But when Monsanto came to NCBS campus to recruit staff for its new R\&D center in Bangalore, she decided it was time to form her own company.

She duly collected Rs9 million ( $\$ 200,000$ at the time) from former students and postdocs, enough to buy equipment and rent laboratory space in a local industrial park. A year later ICICI Ventures and Tata Industries, both of Mumbai, India, pumped \$2 million into Avesthagen. Since then, Patell's drive and leadership have propelled the company's rapid growth: to 250 employees at the latest count.

In the meantime, Patell has not been shy about voicing her concerns over foreign firms' misuse of the Indian patent system. She is particularly critical of the decision of Basel, Switzerland-based Novartis to pur- sue a patent fight with the Indian government regarding the cancer drug Gleevec (imatinib mesylate). Seeking patents for incremental advances is "childish," she says, and patent protection for "limited engineering should be restrained."

The spat centers around India's new patent law, enacted in 2006, that recognizes patent filings made only after 1995. According to India's Office of the Controller, Gleevec is covered by a patent filed in 1993 and is therefore not protected. Novartis is citing a secondary patent filed in 1998 (which claims a version of Gleevec with greater manufacturing stability and bioavailability than the imatinib freebase form), but has not convinced the Indian government that the patent describes derivative forms substantially more effective than the compounds claimed in the 1993 patent.

Novartis has asked the Chennai High Court to strike down the innovation section of the patent law, saying it is inconsistent with the World Trade Organization's Agreement on Trade-Related Aspects of Intellectual Property (TRIPS), of which India is part. TRIPS requires that patentable inventions be new and involve an "inventive step." It allows World Trade Organization members to equate that phrase with the "nonobviousness" claim in US patent law, but it does not mandate it.

"I wanted to create a truly research-based company in India," Patell says.

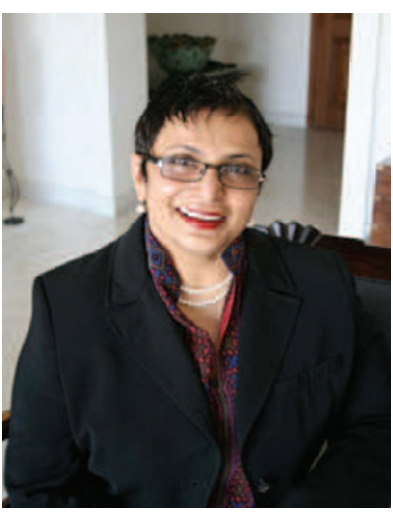

If Novartis wins the case, five or six Indian players in the generics Gleevec field will suffer. Many in the Indian drug industry are thus critical of Novartis's pursuit of the case. Patell agrees, but also adds that 2005 was too early for India to join the TRIPS agreement. "2015 should have been the cut-off point," she says. "That would have given more time for Indian companies to change from being copycats to innovators."

Whatever the problems with Indian patent law, Avesthagen does not seem to be doing badly. Today, it is worth $\$ 1.5$ billion, and, with luck, it will go public by July 2008, making it the second Indian biotech firm to do so after Biocon.

In the meantime, Patell has not forgotten her roots: she belongs to the small community of Parsis (just 69,000 of India's $>1$ billion people) and is worried about hereditary disease rife in the community due to inbreeding. In February this year, she launched a \$30 million genetic study to try to map the hereditary diseases associated with the Parsi bloodline (Nature 446, 475; 2007).

She is also confident of Avesthagen's success. "You must remember that Belgium's Plant Genetic Systems...set up in 1983 by Marc [Van Montagu] did not make money for 18 years. Then he sold it to Hoechst for $\$ 800$ million," she notes. "I am ready to wait."

K S Jayaraman, Hyderabad, India 